\title{
Representing Addition and Subtraction: learning the formal conventions
}

\author{
Introduction \\ Long before children start formal schooling, they can demonstrate an understanding of what number is \\ and of what it can do. They can count small sets of items, and they can add, subtract and share small \\ quantities (Gelman \& Gallistel, 1978; Fuson \& Hall, 1983; Resnick, 1983). Further, they can compare \\ sets and make precise numerical judgements when items have been added to, or subtracted from, a set \\ (Riley et al, 1983). However, while young children's knowledge of number is impressive, it is \\ nevertheless informal (Resnick, 1989), based as it is on everyday experiences where pretend play, role \\ play, images of real world situations and spoken words are the dominant, if not exclusive, forms of \\ representation. When children start school there is an expectation that they will master the formal \\ system of number representation (Kaput, 1987a; Goldin, 1987; Romberg, 1992) since this provides a \\ powerful means of both thinking about, and communicating, the numerical ideas which are embedded \\ in much of our everyday life. However, children do not appear to make the link between their own \\ informal knowledge and the formal conventions of number either easily or automatically (Nunes et al \\ 1993). They may well develop high levels of mechanical accuracy in computation but they are mostly \\ unable to apply their skills to common, everyday experiences in contextualised settings (Skemp, 1971; \\ Lovell, 1972; Brown, 1979; McIntosh, 1981;Biggs, 1983, 1985; Bryant, 1985; Hughes, 1986). This \\ disjunction is typically attributed to pedagogical practices which emphasise symbol manipulation at the \\ expense of conceptual learning. The symbols, and the rules for manipulating the symbols, may be \\ introduced prematurely and/or inappropriately without regard for the numerical ideas which are to be \\ represented by the symbols (Orton \& Frobisher, 1996; Dufour-Janvier et al, 1987). The likely \\ consequence of this is the development of procedures and algorithms which, because they are \\ meaningless to the child, will not be recognised for what they can contribute to learning and problem \\ solving. The confusion which arises from procedural drills which are memorised by rote is not an \\ intended consequence. However, it is not a surprising consequence since learning to manipulate \\ symbols to achieve the approved correct answer "is very hard to distinguish, in its early stages, from \\ conceptual learning" (Skemp, 1971). The essence of the problem then is that the teaching of number in \\ early primary school emphasises the procedures (the rules of usage, the conventions, the linguistic and
}


cipherised symbolism) for effecting operations without due attention to the relationship between a problem context and the necessary computation.

In recent years attempts to narrow the gulf between children's informal knowledge and the formalisms of number have typically involved the use of manipulative materials (Orton \& Frobisher, 1996). It was assumed that experience of concrete materials would enable the child to construct a mental representation of the concept which was being exemplified by the materials. In turn, it was assumed that the construction of some 'mental meaning' from the physical embodiment of the concrete materials would obviate the manipulation of symbols in a rote and mechanical fashion. However, the use of concrete materials has not necessarily produced the intended outcome of meaningful links between procedural and conceptual knowledge (Hall, 1998). Concrete materials can only mediate understanding if the correspondence between the structure of the materials and the structure of the numerical idea is recognised by the child. Furthermore, since numerical meaning does not reside in the materials it has to be imposed on them, which renders the materials themselves to be potential barriers to children's conceptualisation of formal number.

Understanding what is problematic about this state of affairs requires being sensitive to what is involved in the representation of number. While all concept formation requires making abstractions from particular examples and instances, constructing a concept of number requires making abstractions from examples and instances which are themselves not physically denotable. Although it is possible to see the numeral 4 or even count four items, the actual property of number does not reside in either the numeral or in the items. Number is the property of a set or collection of items rather than the property of the individual items within the set or collection. This abstract knowledge can be exemplified in the task of counting. where the individual co-ordinates different pieces of knowledge. Firstly, the individual has to transfer the items from the 'to-be-counted' category to the 'already-counted' category. This transfer may be done mentally or may additionally require the physical pointing to, or moving of, objects from one category to another. Furthermore the transfer is done with one item at a time by assigning a number word once, and once only, to each item. Secondly the words for numbers observe a stable order and the final counting word represents the numerosity of a set. This is not the case for Mary, Joe and Susan who can be referred to in any order but who cannot be collectively summarised by 
any one of the referents Mary, Joe or Susan. Finally the order in which items are counted is irrelevant. An item which is designated 'four' could just as easily be 'six' if the order in which the items were counted was changed. This would not, however, apply to the other properties of an item. Blue cups would continue to be blue cups regardless of their position in a sequence. Understanding what number is and what it can do in relation to the real world is therefore sophisticated knowledge which largely depends on appreciating that the relationship between a number and an item to be counted is arbitrary and temporary.

As we structure and restructure our knowledge about number we need ways of thinking about, and communicating, ideas which are essentially abstract. We can present and (re)present our numerical knowledge to ourselves and others in a variety of forms: as spoken words; as pictures; as written symbols; as real world situations and as manipulative models (Lesh et al 1987). Since these forms support both internal cognitive processing and communication between persons they would appear to be critical to numerical activity. However, it is important that the particular form of representation has meaning for the user in order that he/she can manipulate the numerical idea such that an intention can be realised or a problem solved. A developing sense of number is then the growing capacity to numerically represent objects, events and states internally and externally and to translate reliably and readily between the two (Kaput, 1987a; 1987b).

Although children may well come to school with robust informal knowledge about number, the need to construct the shared system of notational representation is not self evident to the children themselves. Children need help in freeing their thinking from the concrete, and so they need to learn that formalisation is essential. At the same time there is little point in mastering the formal system if understanding is lacking (Hughes, 1986). The cumulative evidence suggests that the value of manipulative materials in mediating understanding is at best unclear and may indeed be adding to the difficulties which children experience in making the transition from total dependence on informal knowledge to the use of the formal notational system (Hall 1998). However such transition is, according to Carpenter \& Moser (1982), of critical importance in the child's subsequent learning of number. If the pedagogical emphasis is on the arithmetical syntax of problems, many children resort to mechanical operations which are only superficially, and often erroneously related to the situation 
described by the problem (Carpenter et al, 1981; Carpenter et al, 1988; Charles \& Lester, 1984;

Garofalo \& Lester, 1985; Hughes, 1986; Treffers, 1991). However, if children can co-ordinate the formal, mathematical notation with their own informal knowledge they can reliably extract a numerical representation from a verbal context and, conversely, they can generate a plausible, if hypothetical, context for a numerical representation. In other words, the child can extract $3+5=8$ from the context, 'Mary has three sweets and her brother gave her five more. Now Mary has eight sweets.' Conversely the child can generate a context such as 'Paul had 5 sweets but then he ate three of them. Now he is left with two sweets' for the numerical representation 5-3=2.

It was this desire to enable children to co-ordinate their own informal, knowledge with the formalisms of the mathematics system which underpinned the study which is reported here. The aim of the study was to test the effects of a structured intervention in teaching children to represent addition and subtraction. The intervention was informed by two assumptions which are pervasive in cognitive/constructivist accounts of mathematical understanding: firstly that informal knowledge serves as a powerful base on which to build more formal knowledge; and secondly, that by linking informal and formal knowledge the learner develops greater 'power' to apply the formal knowledge to a range of situations.

\section{Method}

\section{$\underline{\text { Design }}$}

In a pilot study using 13 children from a reception class the protocol for the intervention was developed. The intervention, named Bi-directional Translation, was then used with an experimental group of reception class children. Using a Post-Test-Only Control Group Design, the effects of Bidirectional Translation were tested. This particular type of design is widely used in educational research because it makes efficient use of time (Verma \& Mallick, 1999). More particularly, however, the post-test only design avoids some of the difficulties associated with either the Pre-Test-Post-Test Control Group Design or the Single Group Pre-Test-Post-Test Design, both of which may yield outcomes that are affected by maturational changes in the subjects and/or the practice effects of pretesting. The constitution of the Experimental and Control Groups is described in the subsection, Subjects, and from this it becomes clear that the design of this study is quasi-experimental rather than 
truly experimental, but this is not to imply that quasi-experiments are necessarily less sound than true experiments.

Some induction of teachers in the protocol of Bi-directional Translation was necessary (its rationale was outlined, guidelines for its implementation were discussed, the necessary materials were provided and arrangements for collecting feedback were made). The children in the experimental group were to be taught the formalisms of addition and subtraction using the protocol of Bi-directional Translation. This was to replace the teacher's own methods for teaching formal addition and subtraction. The children in the control group were to be taught the formalisms of addition and subtraction by whatever means their teachers typically used. Consistent with a world-wide trend (Millett \& Johnson, 1996), typical teaching is assumed to be the total or significant use of a commercial mathematics scheme and a firm focus on the procedural and syntactical elements of addition and subtraction. Teachers in both conditions implemented their teaching within the time allocation for Mathematics which is advised by the local education authority. Teachers in the control schools were advised that their views on the teaching of addition and subtraction would be sought through the completion of a questionnaire, and arrangements were made for return visits to these schools. The possibility of Hawthorne Effects being created in the experimental schools was clearly recognised but was controlled for by focusing the attention of teachers in the control schools on their 'typical teaching' methods at the outset and securing their agreement for a return visit by the researcher. Neither the experimental nor the control group was made aware of the other's participation in the research, and since each group received the same number of visits during the study, each received (at face value) the same amount of researcher attention.

After 'typical teaching' and Bi-directional Translation had been effected, both the control and experimental groups were sampled for their achievements in addition and subtraction. The initial visits were made in January/February and the follow up visits were made in May/June.

\section{$\underline{\text { Subjects }}$}

Subjects were selected in a two-stage process. First appropriate schools were identified and within those schools the subjects were identified. On the basis of information from a large local education authority, twelve schools were selected. The selection criteria are factors which are recognised as being powerful influences on the child's performance in school: 
the geographical location of the school (whether an inner city school or one in a peripheral housing estate)

the cultural composition of the school population (whether the school was mainly monocultural or mainly multicultural)

the economic status of the school population (whether or not the school was designated as being in an area of priority treatment).

Differing permutations of the criteria resulted in schools which could be identified as:

- multicultural/A.P.T./inner city schools,

- multicultural/non A.P.T./inner city schools

- monocultural/A.P.T./inner city schools

- monocultural/non A.P.T./inner city schools

- monocultural/A.P.T./housing estate schools

- monocultural/non A.P.T./ housing estate schools

Having identified how schools could be characterised, two schools of each 'type' were selected by the investigator in consultation with local education authority personnel. Within each pair of schools one was arbitrarily designated as experimental and the other as control, giving six schools in each category. It was recognised that assigning schools as experimental or control was not ideal but since randomisation was logistically impossible in the scale of the study, matching the experimental and control groups was seen as the most equitable compromise. A further compromise was that the subjects tested by the investigator were selected by their class teachers. The investigator requested 15 subjects in each school (making a total of 90 subjects in each of the groups) who:

- had completed the programme of work on addition and subtraction and

- were in the teacher's professional judgement 'good' (5 subjects), 'average' (5 subjects) and 'poor' (5 subjects).

This was a somewhat irregular method for selecting subjects for testing but the investigator was at pains not to give participating teachers the impression that it was they who were being assessed, and so it was considered prudent to have the teachers select the subjects. However, insofar as the groups of subjects were constituted systematically, there was probably little damage to the experiment. 
The age range of the children was as might be typically found in a reception class: 5 years 0 months to 5 years 11 months.

\section{The Independent Variable}

The independent variable was the method of teaching addition and subtraction to which the children were exposed. In the control schools children experienced 'typical teaching' whilst in the experimental schools the children experienced Bi-directional Translation. Key features of this intervention include:

(i) very finely graded steps of progression incorporating what the children themselves bring to the learning situation;

(ii) alternative strategies for dealing with a given situation; for example the choice of using fingers, Unifix Cubes (concrete materials) or tally marks for finding out an answer if the number fact can not be recalled from long term memory;

(iii) verbalisation of operations;

(iv) repeated translation from and to the numerical symbols/hypothetical real world situations.

Further detail on Bi-directional Translation is included in the appendix.

\section{The Dependent Variable}

The dependent variable was performance in addition and subtraction. Performance was deemed to have two elements: knowing when to use a particular operation and knowing how to carry out an operation (Bryant, 1985). Knowing when and knowing how constitute two conditions. To elicit performance, a series of verbal contexts (or 'word problems') was generated according to the classification of CHANGE, COMBINE and COMPARE devised by Riley et al (1983). Each type of word problem can involve addition or subtraction and included items like:

Betty has 3 dollies. Granny gave her 2 more dollies. How many dollies has Betty got now?

(CHANGE involving addition)

Betty had 5 dollies. She gave 2 dollies to her little friend. How many dollies does Betty have now?

(CHANGE involving subtraction)

John has 4 pencils. Joe has 2 pencils. How many pencils do they have altogether? (COMBINE involving addition)

John and Joe have 6 pencils altogether. Joe has 2 pencils. How many pencils does John have?

(COMBINE involving subtraction) 
Neil has 3 toys. He has 2 toys less than Mary. How many toys does Mary have? (COMPARE involving addition)

Neil has 3 toys. Mary has 5 toys. How many more toys does Mary have? (COMPARE involving subtraction)

\section{$\underline{\text { Procedure }}$}

Subjects were tested individually on two different days (with each session lasting no more than 10 minutes): on one day to find out if they knew when to add and subtract and on the other to find out if they knew how to add and subtract. Subjects were instructed to listen carefully to stories read to them and asked either to indicate whether addition or subtraction would solve the problem (for 'knowing when'), or were asked to work out what the answer to the problem was (for 'knowing how'). To counterbalance for order effects, half of the subjects were tested first for 'knowing when' and the other half were tested first for 'knowing how'.

The verbal contexts were read and reread to the subject and, where necessary, repeated. The number domain used was within 10. The desire to minimise potential memorial and computational difficulties reflects the procedure usually adopted in empirical studies of this type (Riley et al, 1983). The order of presentation of verbal contexts was randomised (within conditions) for each subject. Unifix Cubes were available for the subjects' use when being tested for knowing how to add and subtract.

Results

Table 1 Numbers of Correct Responses

\section{ABOUT HERE}

Three findings are immediately discernible from the data. Firstly the experimental subjects performed better (p. $<.005$, one-tailed on the Mann-Whitney U Test) than the control subjects in 'knowing when' to add or subtract. While experimental subjects also scored more than control subjects in 'knowing how' to add and subtract, this difference was not significant. Secondly both experimental and control subjects performed significantly better (p. $<.05$, two-tailed on the Wilcoxon Matched Pairs Test) when required to effect the solution to a problem than when required to determine what was the correct operation. Finally, the problem types were not of equal ease/difficulty. For both experimental and control subjects, there was a significant trend (p. $<.05$ on Page's L Test) from COMBINE problems 
(where performance was highest) through CHANGE problems to COMPARE problems (where performance was poorest). That COMPARE problems are difficult is a consistent finding in the literature (Verschaffel et al, 1992).

\section{Discussion}

The results indicate that children who are exposed to Bi-directional Translation perform better than children who are not. Before going on to consider why this might be so, it is as well to remember the restrictions on group constitution and subject selection imposed by the quasi-experimental design of this study. This means that the group membership has to be considered as a possible source of influence on the results. Furthermore, the sample of subjects, relative to the population from which it was drawn, was small. However, that the experimental and control groups each comprised subjects from across socio-economic and cultural spectrum, attenuates the worst excesses of sample bias. While randomisation in the selection of subjects or in the assigning of subjects to conditions (as would be the case in a true experiment) has powerful consequences for what can be learned from a study, it is equally important to remember that truly-experimental and quasi-experimental designs are both appropriate for the same sorts of research questions and that the complexity of the research design is not an indicator of research quality. Since the intentions of this study were always modest - to find out if a structured intervention based on constructivist principles made any difference to children's learning of addition and subtraction - it is perhaps appropriate to emphasise that this study could be no more than a pilot to determine a research hypothesis for further examination. Within the scope and limits of the present study it is not unreasonable to conclude that while a cautious acceptance of the findings is appropriate, the methodological constraints were not so severe as to render a substantive examination of the results unworthy.

As a structure for teaching children how to meaningfully use the formal, symbolic system for representing addition and subtraction, Bi-directional Translation gives primacy to helping children to make links between their informal knowledge and the formalisms of school mathematics. Ginsburg (1977) argued twenty years ago that for many young children, the gap between their self-invented strategies and the school-taught written procedures for solving addition and subtraction operations was a probable, if partial, reason for the difficulty which children have with school mathematics. Later, 
Hughes (1986) came to a similar conclusion. Hiebert (1984) argued that making the connections between intuitive knowledge and mathematical formalisms was essential if children's meaningful problem-solving approaches were not to degenerate into mechanical and meaningless ones. On the one hand this seems such a simple idea, and yet is so fundamentally important. The concept of translation is perhaps what accounts for the superior performance of the experimental subjects. During the intervention they were repeatedly translating "from actual to hypothetical situations, from concrete to abstract elements, from spoken to written language, from embedded to disembedded thought, from words to symbols and from the informal to the formal" (Hughes, 1986). It is this series of translations, according to Hughes (1986), which must be negotiated if the formal code of arithmetic is to be mastered. The notion of translation is entirely consistent with the constructivist perspective which emphasises that meaningful learning takes place through modifying and building upon existing knowledge and ways of thinking. The learner is actively interpreting incoming information and imposes meaning on this through what extant knowledge structures he/she has. At the same time, the knowledge structures themselves may be modified in order to serve the learner more efficiently. The idea of translation becomes a tool then that the teacher can use because translation is the means by which the learner integrates new information with existing knowledge. Since it is the teacher's task to put children in a position whereby they can construct and reconstruct new forms of knowledge from such knowledge and information as they already possess, teaching children to represent addition and subtraction should draw more strongly on children's intuitive knowledge and on their capabilities for imposing meaning. Bi-directional Translation would seem to allow this.

Another feature of Bi-directional Translation was that it gave equal attention to the computational and conceptual aspects of the operations. This is very different from traditional teaching approaches which give priority to computation in the belief that computation must be well developed before it can be applied real world situations (Carpenter et al, 1989). The results in this study suggest that giving priority to computation is not helpful to children. Similar findings are reported by Villasenor \& Kepner (1993). In their study, children taught using cognitively guided instruction performed significantly better in solving word problems than did those who experienced a diet of "skill drills". What seems to be common to both of those studies is that the superior-performance children were learning in 'social' situations: they had to listen to each other, they could ask each other questions, they had to explain 
themselves to each other. According to Steffe \& Wiegel (1992) this ability to engage in mathematical communication is far from trivial in that it represents assimilating and possibly accommodating to what others are doing in an attempt to construct meaning. At a more general level, Wright (1994) argues that traditional approaches to teaching in early childhood mathematics "significantly underestimate" what the 5 year-old brings to the learning situation. Thus if a conceptually driven approach is considered more 'difficult' (although this is unlikely in the light of the earlier arguments), it may not be too difficult.

What Bi-directional Translation cannot explain is the superior performance in 'knowing how' to add or subtract. Although experimental subjects were clearly superior to control subjects in being able to determine which was the appropriate operation to use, their decisions were, nevertheless, significantly different from their highly accurate computations in equivalent contexts. Had Bi-directional Translation been a completely adequate account of how children make the connections between their own informal knowledge and the formalisms of the notational system, there should have been no significant difference in the performance of the experimental subjects between 'knowing when' and 'knowing how'. That there is some other explanation for the significant difference between 'knowing when' and 'knowing how' is also suggested by the scores of control subjects whose performance pattern mirrored that of the experimental subjects. It is not possible, from this study, to explain this difference though it is possible to speculate. Sowder (1988) argues that a computationally focused curriculum communicates (to both teacher and children) that only the answer is important and that this replaces any intrinsic desires that there might have been to understand. Additionally, he claims that the rewarding of right answerism is compounded by texts and a curricular vision which offer procedural knowledge but little opportunity for constructing conceptual understanding. However plausible this explanation might be for pupils who have experienced only a computationally focused mathematics curriculum, it cannot account for the performance of the experimental subjects in this study who experienced teaching which gave equal attention to the conceptual and computational aspects of addition and subtraction. Perhaps what is really at issue here is the relationship between the publicly shared linguistic expression which is used to denote addition and subtraction, and the internal representation which provides the basis for our thinking about addition and subtraction. In effecting addition and subtraction operations (as in 'knowing how'), there is some real or hypothetical 
interaction with objects in the real world but in thinking about addition and subtraction (as in "knowing when') the action is not on the set of objects themselves but on the representations of these objects. The construction of representations (which allow us to reflect upon, hypothesise about and otherwise manipulate intellectually objects which are not present) is what allows the possibility of thinking (Olson \& Campbell, 1993). However, thinking which, as discussed here, is literally in the abstract may not be well developed in reception class children. Donaldson's (1978) reappraisal of Piagetian work drew attention to the errors or failures made in a 'disembedded' context which simply did not occur when young children were operating in a situation which made 'human sense' to them. Hughes (1986) too showed that when children were required to operate in the abstract, they had no conceptual tools with which to attack the abstract problem but could competently handle elementary arithmetical operations in context. Part of the difficulty with the abstract or disembedded thinking may lie in the specialist meaning which inheres in words which are used mathematically. The everyday meaning (which is the meaning acquired first, Fuson \& Hall, 1983) of add, take away, more or left, for example is different from the mathematical meaning intended by the terms. In situations where there is ambiguity in the meaning of a word, it should perhaps not be surprising that there is a clear tendency to try to interpret the mathematical use in terms of the more familiar and dominant understanding of the word (Durkin \& Shire, 1991). Difficulties which result from differences in what the words are intended to represent may well create difficulties for the young child who is being inducted into the mature activity of making explicit one's mental activity.

\section{Conclusion}

The purpose of the study was to find some means of enabling young children to make sense of school mathematics given that they come to school with a range of mathematical ideas and understandings which have developed informally. Insofar as an experimental group performed better than a control group, limited claims can be made for the effectiveness of the intervention of Bi-directional Translation. These claims would be twofold: firstly in enabling children to make links between their own informal mathematical knowledge and the formalisms of symbolic notation; and secondly in giving equal attention to the conceptual and computational aspects of addition and subtraction. If children are to appreciate that external symbolic representation supports thinking and enables communication about mathematical ideas, they need to understand that the formalisms of mathematics do indeed have real world meaning. Given that children do not come to school with blank numerical 
minds which are devoid of numerical experience, traditional teaching of addition and subtraction (which assumes a tabula rasa state) which emphasises algorithmic procedures may well result in computational competence but does little to help children see or exploit the potential power of the arithmetical operation. However, since children are actually capable of solving simple word problems before they experience formal instruction, what pedagogical practice needs to highlight is the contribution which symbolic notation and manipulation can make to serving the children's extant knowledge base. From the earliest stages of introducing formal number, therefore, there needs to be a focus on real world situations so that the purpose of symbols and their manipulation becomes understood by young children. Bi-directional Translation would seem to go some way to supporting children in the construction of such understanding. Such a claim is made, however, for a study which was no more than a pilot study in that it was limited in its scope and aims. Greater confidence would need to be derived from a larger study.

\section{Acknowledgements}

Funding from the Faculty of Education, University of Strathclyde supported this study.

\section{References}

Biggs, E. (1983) Confident Mathematics Teaching 5-13 (NFER-Nelson, Windsor).

Biggs, E. (1985) Teaching Mathematics 7-13 (NFER-Nelson, Windsor).

Brown, A. (1979) Cognitive development and the learning of mathematics, in Floyd, A. (Ed.) Cognitive Development in the School Years (Croom Helm).

Bryant, P. (1985) The distinction between knowing when to do a sum and knowing how to do it, Educational Psychology 5, Nos. 3\&4, 207-215.

Carpenter, T., Moser, J. \& Hiebert, J. (1981). Problem structure and first grade children's initial solution processes for simple addition and subtraction problems. Journal for Research in Mathematics Education 12(1), 27-39.

Carpenter, T. \& Moser, J. (1982) The Development of Addition and Subtraction Problem-Solving Skills', in Carpenter, T., Moser, J. \& Romberg, T. (Eds.) Addition and Subtraction: A Cognitive Perspective. (Hillsdale NJ: Erlbaum).

Carpenter, T., Moser, J. \& Bebout, H. (1988). Representation of addition and subtraction word problems, Journal for Research in Mathematics Education 19(4), 345-357.

Carpenter, T., Fennema, E., Peterson, P., Chiang, C. \& Loef, M. (1989). Using knowledge of children's mathematics thinking in classroom teaching, American Educational Research Journal 26, 499-531.

Charles, R. \& Lester, F. (1984). An evaluation of a process-oriented instructional program in mathematical problem solving in grades 5 and 7, Journal for Research in Mathematics Education 15(1), 15-34.

Donaldson, M. (1978) Children's Minds (Glasgow: Collins Fontana). 
Dufour-Janvier, B., Bednarz, N, \& Belanger, M. (1987) Pedagogical considerations concerning the problem of representation in: Janvier C (Ed.) Problems of Representation in the Teaching and Learning of Mathematics (Hillsdale NJ: Erlbaum).

Durkin, K. \& Shire, B. (1991) Primary school children's interpretations of lexical ambiguity in mathematical descriptions. Journal of Research in Reading 14(1), 46-65.

Fuson, K \& Hall, J. (1983) The acquisition of early number word meanings in: Ginsburg H (ed.) The Development of Mathematical Thinking (London, Academic Press).

Garofalo, J. \& Lester, F. (1985). Metacognition, cognitive monitoring, and mathematical performance. Journal for Research in Mathematics Education 16(3), 163-176.

Gelman, R. \& Gallistel, C. (1978) The Child's Understanding of Number (Cambridge, MA, Harvard University Press).

Ginsburg, H. (1977) Children's Arithmetic_(New York, Van Nostrand).

Goldin, G (1987) Levels of language in mathematical problem solving in C. Janvier (Ed.) Problems of Representation in the Teaching and Learning of Mathematics (Hillsdale NJ: Erlbaum).

Hall, N. (1998) Concrete representations and the procedural analogy theory, Journal of Mathematical Behaviour 17(1), 33-51.

Hegarty, M., Mayer, R. \& Monk, A. (1995). Comprehension of arithmetic word problems: a comparison of successful and unsuccessful problem-solvers. Journal of Educational Psychology 87(1), 18-32.

Hiebert, J. (1984). Children's mathematical learning. The Elementary School Journal 84(5), 497-513.

Hughes, M. (1986) Children and Number. (Oxford, Basil Blackwell).

Kaput, J. (1987a) 'Representation systems and mathematics' in: Janvier, C. (Ed.) Problems of Representation in the Teaching and Learning of Mathematics (Hillsdale NJ: Erlbaum).

Kaput, J. (1987b) Towards a theory of symbol use in mathematics in: Janvier, C. (Ed.) Problems of Representation in the Teaching and Learning of Mathematics (Hillsdale NJ: Erlbaum).

Lesh, R., Post, T. \& Behr, M (1987) Representations and translations among representations in mathematics learning and problem solving in: Janvier, C. (Ed.) Problems of Representation in the Teaching and Learning of Mathematics (Hillsdale NJ: Erlbaum).

Lovell, K. (1972) Intellectual growth and understanding mathematics, Journal for Research in Mathematics Education 3, 164-182.

McIntosh, A. (1981) When will they ever learn? In: Floyd A. (Ed.) Developing Mathematical Thinking. (Addison-Wesley).

Millett, A. \& Johnson, D. (1996) Solving teachers' problems? The role of the commercial mathematics scheme in: Johnson, D. \& Millett, A. (Eds.) Implementing the Mathematics National Curriculum (London, Paul Chapman Publishing).

Nunes, T., Schliemann, A. \& Carraher, D. (1993) Street Mathematics and School Mathematics. (New York, Cambridge University Press).

Olson, D. \& Campbell, R. (1993) Constructing representations in: Pratt, C. \& Garton, A. (Eds.)

Systems of Representation in Children (Chichester, John Wiley \& Sons).

Orton, A. \& Frobisher, L. (1996) Insights into Teaching Mathematics. (London, Cassell). 
Resnick, L. (1983) A developmental theory of number understanding in: Ginsburg H. (Ed.) The Development of Mathematical Thinking (London, Academic Press).

Resnick, L. (1989) Developing mathematical knowledge, American Psychologist 44(2), 162-169.

Riley, M., Greeno, J. \& Heller, J. (1983). Development of children's problem solving ability in arithmetic in: Ginsburg H. (Ed.) The Development of Mathematical Thinking (London, Academic Press).

Romberg, T. (1992) Assessing mathematics competence and achievement in Berlak, H., Newman, F. Adams, E., Archbald, D., Burgess, T., Raven, J. \& Romberg, T. (Eds.) Toward a New Science of Educational Testing and Achievement (Albany, State University of New York Press

Skemp, R. (1971) The Psychology of Learning Mathematics (Harmondsworth, England, Penguin Books).

Sowder, L. (1988) Children's solutions of story problems. Journal of Mathematical Behaviour 7, 227238.

Steffe, L. \& Wiegel, H. (1992). On reforming practice in mathematics education, Educational Studies in Mathematics 23, 445-465.

Treffers, A. (1991). Meeting innumeracy at primary school, Educational Studies in Mathematics 22, 333-352.

Verma, G. \& Mallick, K (1999) Researching Education (London, Falmer Press).

Verschaffel, L., De Corte, E. \& Pauwels, A. (1992) Solving compare problems, Journal of Educational Psychology 84(1), 85-94.

Villasenor, A. \& Kepner, H. (1993). Arithmetic from a problem-solving perspective, Journal for Research in Mathematics Education 24(1), 62-69.

Wright, R. (1994) A study of the numerical development of 5-year-olds and 6-year-olds, Educational Studies in Mathematics 26, 25-44. 


\section{Appendix 1}

Notes on the Protocol for Bi-directional Translation (Series of steps for teaching addition)

Step I Setting the scene.

Children are seated round the table, each child having a stack of 10 Unifix Cubes. The children are asked to take (say) two cubes from their stacks. A magnetic numeral ' 2 ' is displayed on the magnet board. Attention is drawn to the two cubes in front of each child and to the numeral ' 2 ' on the board. The children are told that they are to take more cubes from their stacks and that to show on the board that they are taking more cubes, a sign is used. The children are told that the sign says 'plus' or 'add on'. The magnetic ' + ' is affixed to the board. The children are now asked to take a further three cubes from their stacks and to sit them beside the two cubes. A magnetic ' 3 ' is displayed on the board.

Attention is drawn to the cubes in front of the children and to the display on the board. The children are asked to find out how many cubes they took from the stack altogether. After the total has been ascertained, the teacher explains that another sign is needed to show that something has been found out about $2+3$. The children are told that the sign says 'equals' or 'makes' or 'is the same as'. The magnetic $'=$ ' is affixed to the board as is the magnetic ' 5 '.

Attention is drawn to the cubes in front of the children and to the 'number story' on the board (two plus three equals five). The children are invited to read' the number story aloud. This entire procedure is repeated many more times over successive days using different number combinations within 10. Zero is introduced by instructing the children to take out 4 cubes and then take out no cubes.

Step 2 Let's Pretend.

The children are introduced to the notion that cubes can be used to represent just about anything in the real world. The teacher says to the children, "Let's pretend the cubes are bananas" or "cars" or whatever. The children are instructed to take out three bananas and then another three bananas and to find out how many bananas they have in front of them. Every addition activity is accompanied by its representation in magnetic numeral form.

Step 3 Silly Stories.

The children are told to listen to a 'silly story' and to take from their stack of cubes the numbers mentioned in the 'silly story'. The teacher prompts the children for the 'conclusion' and when this has been identified asks, "How did you find out the answer?"

Step 4 Silly Stories and Number Stories.

The teacher provides a complete 'silly story' and the children are invited to use the magnetic numerals and signs to represent the 'silly story' as a 'number story'. The children 'read' the 'number story' and are required to indicate how the different symbols in the 'number story' match the elements of the 'silly story'.

Step 5 Number Stories and Silly Stories.

The teacher provides a complete 'number story' on the magnet board (for example $1+3=4$ ) and the children are invited to provide a corresponding 'silly story'.

Step 6 Drawing a story - first version.

The children are instructed that instead of telling a 'silly story' they have to draw a 'silly story' for a bit of a number story which will be provided. The instruction 'draw $2+3$ ' is given orally and is also put on the magnet board for the children to see. When each child has pictorially represented his/her 'silly story' ask the child to explain his/her story and scribe the story in front of the child.

Step 7 Drawing a story - second version. 
The children are invited to draw their own 'silly story' with no numerical stimulus being provided. In other words the children are not told of how many of each sub set to draw. The teacher again scribes at the child's dictation.

Step 8 Strategies for finding the answer.

The children are told that they will be given a bit of a 'number story' (for example $3+4=$ ) and that they will have to find the answer. Possible means of finding the answer (using fingers, using cubes, drawing pictures) are discussed. The teacher, further, demonstrates the use of tally marks. The results are compared using each of the methods. The children are given practice in setting down 'number stories' and in finding the answers by whichever method(s) they choose. 
Table 1 Numbers of Correct Responses

\begin{tabular}{|c|c|c|c|c|c|}
\hline Problem Type & \multicolumn{2}{|c|}{ KNOWING WHEN } & \multicolumn{2}{|c|}{ KNOWING HOW } & \\
\hline & Exp. Ss & Control Ss & Exp. Ss & Control Ss & TOTALS \\
\hline CHANGE + & 75 & 6 & 80 & 65 & 226 \\
\hline CHANGE - & 64 & 3 & 77 & 36 & 180 \\
\hline COMBINE + & 87 & 15 & 89 & 81 & 272 \\
\hline COMBINE - & 64 & 4 & 85 & 37 & 190 \\
\hline COMPARE + & 48 & 3 & 62 & 11 & 124 \\
\hline COMPARE - & 10 & 0 & 34 & 5 & 49 \\
\hline Mean & 58 & 5.2 & 71.2 & 39.2 & \\
\hline
\end{tabular}

